\title{
Adaptive variation and plasticity in nonstructural carbohydrate storage in a temperate tree species
}

\author{
Meghan Blumstein ${ }^{1}$ and Robin Hopkins ${ }^{2}$ \\ ${ }^{1}$ Massachusetts Institute of Technology \\ ${ }^{2}$ Harvard University Faculty of Arts and Sciences
}

October 26, 2020

\begin{abstract}
Trees' total amount of nonstructural carbohydrate (NSC) stores and the proportion of these stores residing as insoluble starch are vital traits for individuals living in variable environments. However, our understanding of how stores vary in response to environmental stress is poorly understood as the genetic component of storage is rarely accounted for in studies. Here, we quantified variation in NSC traits in branch samples taken from over 600 clonally transplanted black cottonwood (Populus trichocarpa) trees grown in two common gardens. We found heritable variation in both total NSC stores and the proportion of stores in starch $(\mathrm{H} 2 \mathrm{TNC}=0.19, \mathrm{H} 2 \mathrm{PropStarch}=0.31)$, indicating a substantial genetic component of variation. In addition, we found high amounts of plasticity in both traits in response to cold temperatures and significant genotype-by-environment (GxE) interactions in the total amount of NSC stored ( $54 \%$ of $\mathrm{P}$ is GxE). This finding of high GxE indicates extensive variation across trees in their response to environment, which may explain why previous studies of carbohydrate stores' responses to stress have failed to converge on a consistent pattern. Overall, we found high amounts of environmental and genetic variation in NSC storage concentrations, which may bolster species against future climate change.
\end{abstract}

Title: Adaptive variation and plasticity in nonstructural carbohydrate storage in a temperate tree species

Running Head: gen. \& env. variation in carbohydrate storage

Authors: M. Blumstein ${ }^{1, *} \&$ R. Hopkins ${ }^{1,2}$

Affiliations:

${ }^{1}$ Department of Organismic and Evolutionary Biology, Harvard University, 26 Oxford St, Cambridge, MA 02138, USA

${ }^{2}$ The Arnold Arboretum, 1300 Centre St, Boston, USA 02130

* Correspondence to: mblumsete@mit.edu

\section{Funding:}

This material is based upon work supported by the U.S. Department of Energy, Office of Science, Office of Workforce Development for Teachers and Scientists, Office of Science Graduate Student Research (SCGSR) program, by the National Science Foundation Graduate Research Fellowship under Grant No. DGE1745303, and the Explorer's club. The SCGSR program is administered by the Oak Ridge Institute for Science and Education (ORISE) for the DOE. ORISE is managed by ORAU under contract number DE-SC0014664. Support for the establishment, maintenance and genetic resources of the Populus common gardens was provided by the Center for Bioenergy Innovation (CBI), a Bioenergy Research Center supported by the Office of Biological and Environmental Research in the U.S. Department of Energy Office of Science. 


\begin{abstract}
Trees' total amount of nonstructural carbohydrate (NSC) stores and the proportion of these stores residing as insoluble starch are vital traits for individuals living in variable environments. However, our understanding of how stores vary in response to environmental stress is poorly understood as the genetic component of storage is rarely accounted for in studies. Here, we quantified variation in NSC traits in branch samples taken from over 600 clonally transplanted black cottonwood (Populus trichocarpa) trees grown in two common gardens. We found heritable variation in both total NSC stores and the proportion of stores in starch $\left(\mathrm{H}^{2} \mathrm{TNC}=0.19\right.$, $\mathrm{H}^{2}$ PropStarch $=0.31$ ), indicating a substantial genetic component of variation. In addition, we found high amounts of plasticity in both traits in response to cold temperatures and significant genotype-by-environment $(\mathrm{GxE})$ interactions in the total amount of NSC stored (54\% of P is GxE). This finding of high GxE indicates extensive variation across trees in their response to environment, which may explain why previous studies of carbohydrate stores' responses to stress have failed to converge on a consistent pattern. Overall, we found high amounts of environmental and genetic variation in NSC storage concentrations, which may bolster species against future climate change.
\end{abstract}

\title{
Keywords:
}

Nonstructural carbohydrates, climate change, plasticity, adaptation, temperate forests, ecophysiology, Populus trichocarpa (black cottonwood)

\section{Acknowledgements:}

We thank D.L. DesMarais for comments, A.Viser, E.Borjigin-Wang, and A.Chan for lab assistance, D. Weston and L. Gunter for project assistance, and C.F. White for field assistance.

\section{Introduction}

Climate is changing and extreme temperature and precipitation events are expected to intensify over the coming century (IPCC, 2013a), presenting immense challenges for immobile, long-lived organisms such as trees. Rates of forest tree mortality are already increasing worldwide as a result of shifting drought regimes, extreme temperatures, and pest outbreaks associated with global change (Allen et al., 2010; Anderegg et al., 2015; Anderegg et al., 2016; McDowell et al., 2018). In response to change, individual plants may physiologically adjust by plastically altering traits in the short term (Anderson, Inouye, McKinney, Colautti, \& Mitchell-Olds, 2012; Des Marais, Hernandez, \& Juenger, 2013; Pritzkow, Williamson, Szota, Trouve, \& Arndt, 2020; Valladares et al., 2014; Valladares, Sanchez-Gomez, \& Zavala, 2006; Wortemann et al., 2011), while populations may undergo local adaptive evolution through shifts in their genetic composition over longer time scales (Aitken, Yeaman, Holliday, Wang, \& Curtis-McLane, 2008; Davis, Shaw, \& Etterson, 2005). Thus, understanding the extent to which trees are able to alter their traits in response to climatic change over short (plastic) and long (evolutionary) timescales is critical to predicting species' survival.

One key trait that enables plants to tolerate stochastic environments is the storage of nonstructural carbohydrates (NSCs). NSCs are the sugars and starches produced via photosynthesis and stored in the parenchyma cells of plants' woody tissues for later use (Chapin III, Schulze, \& Mooney, 1990; Plavcová \& Jansen, 2015). NSCs fuel respiration at night, leaf-out in spring, and are also thought to serve as a back-up osmolytic or energetic reserve during periods of environmental extremes, like drought or freezing temperatures (Adams et al., 2017; Chapin III et al., 1990; H. Hartmann \& Trumbore, 2016; McDowell et al., 2008; Sevanto, McDowell, Dickman, Pangle, \& Pockman, 2014). Total NSC storage concentrations are known to vary seasonally (eg. Furze et al., 2019), across species (eg. Martínez-Vilalta et al., 2016), and within species (eg. Blumstein et al., 2020) and this variation in NSC storage concentrations has been linked to prolong survival under drought(O'Brien, Leuzinger, Philipson, Tay, \& Hector, 2014). However, what controls variation in total NSC stores and how sensitive it is to environment is still poorly understood. Thus, we are limited in our ability to predict whether forest trees will be able to vary NSC stores in order to tolerate or adaptively evolve in response to climate change.

Total NSC stores can be broken down into two categories: soluble sugars and insoluble starches (Kaplan 
\& Guy, 2004; Krasensky \& Jonak, 2012; Thalmann \& Santelia, 2017). Sugars affect cells' osmotic balances and are readily accessible for metabolism as they are dissolved in solution, while starches are considered the longer-term storage molecule as they are insoluble and thus must be broken back down into sugar to be used by the cell as an osmolyte or metabolite. Sugars can hydrolyze into and out of starch form via a number of enzymatic pathways (Thalmann \& Santelia, 2017). The rate of starch formation and degradation varies daily (A. Tixier, Orozco, Roxas, Earles, \& Zwieniecki, 2018), seasonally (Furze et al., 2019; Martínez-Vilalta et al., 2016; Richardson et al., 2013; Wurth, Pelaez-Riedl, Wright, \& Korner, 2005), by plant tissue (Furze et al., 2019; Martínez-Vilalta et al., 2016), and in response to stress, such as water deficit (Adams et al., 2017; Landhäusser \& Lieffers, 2011; Mitchell et al., 2013; Sevanto et al., 2014), high salinity (Chen, Chen, \& Wang, 2007; Goyal, 2007; Kanai et al., 2007; Kempa, Krasensky, Dal Santo, Kopka, \& Jonak, 2008; Ma et al., 2013), or extreme temperatures (Hoermiller et al., 2017; Kaplan \& Guy, 2005; Nagao, Minami, Arakawa, Fujikawa, \& Takezawa, 2005; Vasseur, Pantin, \& Vile, 2011). Under environmental stress, starch is degraded, leading to a subsequent rise in soluble sugars in stressed tissues (Thalmann \& Santelia, 2017) and an increased ability to withstand the applied stress. Thus, a plant's ability to convert NSC stores from starch to sugars, and back again, is an important consideration for survival under climate change. While variation in starch degradation rates in response to environmental cues is well documented, it is not yet understood if individuals exhibit differential sensitivities to these cues, indicating a potential for adaptive evolution in response to increased stress.

Given that both the total amount of NSC stores a plant holds and the proportion of those stores reserved in starch can play crucial roles in woody plant survival under environmentally induced stress, measuring the degree of heritable genetic and plastic variation in these traits will be critical for predicting tree species' persistence under climate change. Transplant experiments across multiple sites with replicate clones or related individuals can be used to disentangle sources of variation (Josephs, Berg, Ross-Ibarra, \& Coop, 2019; Nuismer \& Gandon, 2008). Genetic variation in these designs is measured within an environment across unique genotypes, while plastic variation is measured across environments within unique genotypes. In practice, because measuring plastic variation results in the additional capture of genetic variation by virtue of gathering data from multiple common environments, it is often broken down into three components; variation within a garden attributed to genetic differences $(\mathrm{G})$, variation between gardens attributed to environmental plasticity (E), and the interaction between genotype and environment (GxE) (ie. some genotypes can be more plastic than others). While there is strong evidence that heritable genetic variation is responsible for some of the variation in NSCs in some trees such as Populus trichocarpa(Blumstein et al., 2020) and Pinus sylvestris (Oleksyn, Zytkowiak, Karolewski, Reich, \& Tjoelker, 1999), to our knowledge, no study to date has quantified the extent of plastic variation in NSCs. Furthermore, no study has examined genetic or plastic variation in the proportion of NSC that is kept in starch versus sugar, a potentially critical aspect of plant response to stress.

By partitioning the variation in NSCs we can not only predict the potential for tress to respond to increased prevalence of stress, we can also begin to understand if trees are already locally adapted to variation in environmental stress across their ranges. If greater total NSC storage and more rapid transition between starch and sugar storage can increase survival in stressful events, we predict genetic variation in these traits to reflect geographic variation in stress. By controlling for neutral population genetic variation across the range of a tree species (e.g. Fst) we can determine the extent to which traits show genetic differentiation (e.g. Qst) reflective of local adaption.

Here, we measure genetic and plastic variation in total NSC storage and the proportion of NSC stores held in insoluble starch versus soluble sugars. To do so, we utilized two Department of Energy (DOE) common gardens of black cottonwood (Populus trichocarpa) growing in the western United States. Each garden contains clonally replicated genotypes from multiple populations across the species range. We extracted sugars and starches from branch woody tissue of trees grown in two common gardens located at similar latitudes, but spanning a continental to coastal environmental cline (Figures $1 \& 2 \mathrm{~A}$ ). Our objective is to understand the acclimatory and evolutionary potential of black cottonwood trees under future climate change. We accomplish this by parsing the amount of phenotypic variation attributable to genetic variation $(\mathrm{G})$, environmental 
plasticity (E), and genotype-by-environment interactions ( $\mathrm{GxE}$ ) for both the total concentration of NSC stores, as well as the proportion of total stores in insoluble starch. In addition, we search for signatures of current local adaptation in both traits across the environmental gradient of source populations.

\section{Materials and Methods}

\section{Sample collection}

We collected branch samples from two Department of Energy (DOE) common gardens in Oregon, USA in January of 2017. The gardens are located near Clatskanie, Oregon $\left(46.12 @ \mathrm{~N}, 123.27 @ \mathrm{~W} ; \mathrm{MAT}=10.4^{\circ} \mathrm{C}\right.$, MAP $=1,545 \mathrm{~mm}$ ) and Corvallis, Oregon $\left(44.56 @ \mathrm{~N}, 123.26 @ \mathrm{~W} ; \mathrm{MAT}=11.2^{\circ} \mathrm{C}, \mathrm{MAP}=1,030 \mathrm{~mm}\right)$ respectively, which represent contrasting environments with similar daylength patterns (Figure 2A). Each garden contains the same $1,000^{+}$unique genotypes, collected as branch cuttings from individuals located in 19 native populations (Figure 1). These cuttings were replicated clonally 3 times each and planted out in three randomized replicates in 2009, for a total of approximately 3,000 trees in each garden. The collection of each accession is described in Slavov et al. (2012) and their full genomic sequences are available on phytozome (Evans et al., 2014). In the winter of 2013-2014, all replicates in Corvallis and one replicate in Clatskanie were coppiced (aboveground biomass harvested) (Figure 1).

We sampled from a subset of the total 3,000 individuals per garden due to the high cost of NSC analysis in both time and lab disposables. In order to parse heritable variation, we aimed to sample all of the replicates of the same three to five genotypes from each population across the two gardens (Table S1). However, some populations had high mortality, leading us to eventually exclude the two latitudinally extreme populations from the final analysis of plasticity due to lack of replication (Kitimat \& Tahoe). In all we sampled 245 individuals representing 64 unique genotypes (Table S1). To this dataset, we added samples collected across a genomically diverse set of individuals in Corvallis that added substantially to the number of genotypes measured per each population (Table S1). These additional samples provided much more power for parsing within versus among population variation, a requisite step for assessing local adaptation. The result was a total of 551 individuals from 392 unique genotypes sampled in Corvallis and 65 individuals from 64 unique genotypes sampled in Clatskanie (Table S1). We accounted for uneven replicate and within population sampling in our models described below.

We collected branch wood samples from coppiced replicates between January $6^{\text {th }}$ and January $11^{\text {th }} 2017$, between 7 A.M. and 4 P.M. using pruning shears. We took all branch samples as $2 \mathrm{~cm}$ segments from the previous growing season's growth segment (2015) of coppiced replicates as it was accessible across all individuals. All samples were kept on dry ice during field collection, then shipped overnight to Cambridge, MA and stored at $-80^{\circ} \mathrm{C}$. In total, we collected and processed 616 branch samples (Figure 1). We collected additional stem and root tissue during this time period and included aspects of this work in the discussion for comparison (Blumstein et al., 2020)(Table S2). Non-coppiced trees in Clatskanie had an average diameter at breast height $(\mathrm{DBH})$ in 2016 of $155.2 \pm 46.9 \mathrm{~mm}$, while coppiced trees averaged $84.0 \pm 28.0 \mathrm{~mm}$. DBH in Corvallis across all coppiced replicates in 2016 was $44.4 \pm 14.9 \mathrm{~mm}$.

\section{NSC Laboratory Preparation}

We initially freeze-dried samples for 24-hours (FreeZone 2.5; Labconco, Kansas City, MO, and Hybrid Vacuum Pump, Vacuubrand, Wertheim, Germany), then ground them to a fine powder (mesh 10, Thomas Scientific Wiley Mill, Swedesboro, NJ, USA; SPEX SamplePrep 1600; MiniG, Metuchen, NJ) and stored them in sealed glass vials. Sugar and starch extraction protocols were adapted from Chow \& Landhäusser (2004).

We extracted sugar from $20 \mathrm{mg}$ of dried, ground tissue using $80 \%$ hot ethanol, followed by a colorimetric assay with phenol and sulfuric acid, and read using a spectrophotometer at 490nm (Thermo Fisher Scientific GENESYS 10S UV-Vis, Waltham, MA). We calculated sugar concentrations of mg sugar per g of dry wood using a 1:1:1 glucose-fructose-galactose standard curve (Sigma Chemicals, St. Louis, MO). We extracted starch using the tissue remaining after sugar extraction. We solubilized tissue in $\mathrm{NAOH}$, then incubated it for 24-hours with alpha-amylase and amyloglucosidase digestive enzymes, which digested starch into glucose. 
We then assayed the solutions using a PGO-color reagent solution (Sigma chemicals) and read them on the spectrophotometer at $525 \mathrm{~nm}$. Starch concentrations of $\mathrm{mg}$ glucose-starch-equivalent per $\mathrm{g}$ dry wood were calculated based on a glucose standard curve (Sigma Chemicals).

For all lab analyses, we included at least two internal laboratory standards (Quercus rubra stemwood from Harvard Forest, MA; $42.01 \pm 5.13 \mathrm{mg}^{*} \mathrm{~g}-1$ Sugar, $30.17+-4.23 \mathrm{mg}^{*} \mathrm{~g}-1$ starch). This acid methodology extracts all fructose, glucose, sucrose, and starch, as well as other oligosaccharides and other glucans (Landhausser et al., 2018). We then report these metrics as sugar and starch concentrations (mg*g-1) in the supplement, as well as the total nonstructural carbohydrates (TNC) concentration (sugar + starch) and theproportion of starch to total ( starch/ (sugar + starch)) in the main text. All statistical analyses were performed in $R \mathrm{v} .3 .5 .1$ (R. C. D. Team, 2018). Note our focus on the proportion of starch to total stores is an important one, as just looking at starch gives an incomplete picture of change. Sugar concentrations are positively correlated with starch concentrations, thus "normalizing" by total helps us to isolate whether the amount in starch is genuinely changing.

\section{Determining environmental conditions of population origins and gardens}

We accessed Daymet daily meteorological data for the past 38 years (1980-2018) at each site via the daymetr package in R(Hufkens, Basler, Milliman, Melaas, \& Richardson, 2018). Daymet data are $1 \mathrm{~km}^{2}$ gridded estimates of daily weather variables, interpolated from weather station data(Thornton et al., 2018). Using these data, we calculated common descriptive climate variables that represent the temperature and aridity of our genotype provenances and 2 common garden sites. All climatic variables we calculated were highly colinear, thus we used a PCA analysis to describe the major axes of variation via the vegan v.2.5-3 package in R (Oksanen et al., 2018) (Figure 2A).

\section{Control for spatial autocorrelation}

In common garden studies the spatial autocorrelation, or the probability that individuals growing closer together are more similar, of samples must be taken into account (Stopher et al., 2012). To account for spatial patterns within each of our gardens (Clatskanie and Corvallis), we used a thin-plate spline method (Blumstein et al., 2020; Evans et al., 2014) via the fields (9.6) (Nychka, Furrer, Paige, \& Sain, 2017) package in $R$. This method fits an interpolated surface to the garden, which uncovers regions of each site that significantly differ from the mean. To correct these patterns of spatial concordance, we take the residuals from the thin plate spline and add them back to the model intercept, thus removing spatial trends and placing sample values back on a biologically meaningful scale. We did this for each of our metrics independently; sugar concentration, starch concentration, total nonstructural carbohydrate (TNC) concentration, the proportion of starch (starch / TNC), and diameter at breast height (DBH).

\section{Calculating the genetic contribution via heritable variation}

We estimated components of variation across all the data from both gardens to calculate broad-sense heritability and $\mathrm{Q}_{\mathrm{st}}$. To account of the lack of replication in Clatskanie, we combined measurements from both gardens into the model and thus used the pooled data to parse within genotype variation and make our genotypic estimates, or "BLUPs". This within genotype variation was coded as residual variation in the model $\left(\varepsilon_{\text {Gipg }}\right)$ and captures both microenvironmental variation and measurement error in the estimate. Thus, genotypic estimates from the model are the end result after microenvironmental and measurement error are removed (Figures $3 \& \mathrm{Sx}$ ).

The spatial autocorrelation corrected data were used to parse variation in our nested hierarchical structure of population, genotype, and environment via the following equations:

$$
\text { (1) } Y_{\mathrm{Gigp}}=s s_{G}+\alpha_{G}+\alpha_{\mathrm{Gp}}+\alpha_{\mathrm{Gpg}}+\varepsilon_{\mathrm{Gipg}}
$$

Our goal is to quantify within-garden genetic variation, we therefore parsed variation in branches grown in two different gardens $(\mathrm{G})$ using the fixed effect $s s_{G}$. The parameters $p$ for population (i.e. provenance of 
genotype), g for genotype, and $i$ for the $i^{\text {th }}$ individual tree sampled are all random effects. All branch data were modeled as gamma distributions using Bayesian mixed regression models via the package rstan v.2.18.2 in (T. S. D. Team, 2014). We chose to evaluate our model using Bayesian methods as it allowed us to fully quantify the uncertainty associated with uneven sampling across the gardens. The random effects outcomes $\left(\alpha^{\prime} s\right)$ and fixed effect $\left(s s_{G}\right)$ of equation (1) were estimated as the mean of 6,000 random draws from the posterior distribution (Table $1 \& \mathrm{~S} 3$ ).

The resultant fixed and random effect estimates $\left(s s_{G}+\alpha_{G}+\alpha_{\mathrm{Gp}}+\alpha_{\mathrm{Ggp}}\right)$ from equation 1 were then used as our genetic estimate for each genotype and are displayed in all graphical analyses (often referred to as a Best Linear Unbiased Prediction or BLUP). The variation parameters estimated from equation 1 were used to calculate broad-sense heritability, $\mathrm{H}^{2}$, and $\mathrm{Q}_{\mathrm{st}}$ of each of the traits. $\mathrm{H}^{2}$ was calculated for all traits in stems, branches, and roots, using the random effects variances from equation (1) as:

$(2)\left(\sigma_{\text {Genotype }}^{2}+\sigma_{\text {Population }}^{2}\right) /\left(\sigma_{\text {Population }}^{2}+\sigma_{\text {Genotype }}^{2}+\sigma_{\text {Microenvironment }}^{2}\right)$

Population variance was included with Genotype as it is also representative of genetic differences between individuals. Genotype variance was taken as the variance among replicates and microenvironmental variance was taken as the residual variance of the model. $Q_{\text {st }}$ was calculated via the formula (Spitze, 1993; Whitlock \& Gilbert, 2012):

(3) $\sigma_{\text {Population }}^{2} /\left(2 \sigma_{\text {Genotype }}^{2}+\sigma_{\text {Population }}^{2}\right)$

$\mathrm{F}_{\mathrm{st}}$ was taken from a previous publication using the same genotypes and calculated in 1-kb windows as $\left(\pi_{\mathrm{T}^{-}}\right.$ $\left.\pi_{\mathrm{S}}\right) / \pi_{\mathrm{T}}$; where $\pi_{\mathrm{T}}$ is SNP diversity across all individuals and $\pi_{\mathrm{S}}$ is weighted within-population SNP diversity (Evans et al., 2014).

\section{Calculating plasticity: environmental and genotype-by-environment contribution}

Plastic variation is defined by Scheiner and Goodnight as the variation due to environment (E) and genotypeby-environment (GxE) interactions (Scheiner \& Goodnight, 1984). Again, we use the pooled data to estimate within genotype variation (microenvironmental \& measurement error). To calculate each, we used a Bayesian mixed model regression analysis in $\mathrm{R}$ using the rstanarm v. 2.19.2 package(Goodrich, Gabry, Ali, \& Brilleman, 2019) via the following equation.

$$
\text { (4) } Y_{\mathrm{igG}}=\alpha_{G}+\alpha_{g}+\alpha_{G: g}+\varepsilon_{\mathrm{igG}}
$$

The model calculates the variation within the random effects of Environment (G or Garden), Genotype (g), and GxE (G:g, or Garden:genotype) (Table S3). We then use these variances, estimated as the mean of 6,000 random draws from the posterior distribution of equation (4), to calculate the contribution of an individuals' phenotype due to plasticity, also known as the $S$ indexv(Scheiner \& Lyman, 1989).

$$
\text { (5) } S=\left(\sigma_{E}^{2}+\sigma_{\mathrm{GxE}}^{2}\right) /\left(\sigma_{G}^{2}+\sigma_{\mathrm{GxE}}^{2}+\sigma_{E}^{2}+\sigma_{e}^{2}\right)
$$

We then used these properties to calculate the proportion of plasticity due to environment versus genotypeby-environment interactions (Table 2).

$$
\text { (6) } \sigma_{\text {Plasticity }}^{2}=\left(\sigma_{E}^{2}+\sigma_{\mathrm{GxE}}^{2}\right)
$$

We build this model separately from our heritability model because of the way $\mathrm{H}^{2}$ and $\mathrm{S}$ are defined in the literature. Plasticity (S) estimates require us to separate variation due to GxE interactions from genetic variation. However, GxE interactions would be partially captured under the umbrella of genetic variation in our heritability model. Conversely, our heritability model also examines the variation due to population in order to calculate $\mathrm{Q}_{\mathrm{st}}$, which is partially captured by the $\mathrm{G}$ and $\mathrm{GxE}$ random effect terms from our plasticity 
model. In order to accurately parse the subtle differences in how heritability and plasticity define genetic variation, we run two separate models.

We also used Relative Distance Plasticity Index (RDPI) as a measure of genotypic plasticity, which is a more general way of calculating plasticity that doesn't rely on assumptions of the underlying distribution of the data(Valladares et al., 2006) .

$$
\text { (7) } R D P I=\sum \frac{\left|X_{\text {Clatskanie }}-X_{\text {Corvallis }}\right|}{\max \left(X_{\text {Clatskanie }}, X_{\text {Corvallis }}\right)} / N
$$

RDPI measures the absolute difference in genetic trait values between genotypes grown in two different environments, then normalizes that measure by the maximum of the two values. All of these measures are then summed and divided by the number of samples to get the final average RDPI metric.

\section{Results}

\section{Environmental conditions of population origins and gardens}

Our genotypes originated from a steep climatic gradient of temperature (mean annual temperature: 10$17^{\circ} \mathrm{C}$ ), aridity (mean annual precipitation: $609 \mathrm{~mm}-2,705 \mathrm{~mm}$ ), and continentality (temperature difference between hottest and coldest month: $14-26^{\circ} \mathrm{C}$ ). When summarized via a Principle Components Analysis (PCA), the first major axis of variation amongst climate variables across sites (PC1) describes an axis of cold and wet sites to hot and dry sites (Figure 2A). The second axis of variation represents continentality, ranging from sites with consistently cold winters and high amounts of snowfall to sites that are generally warmer and do not experience as extreme lows (Figure 2A). In comparison to Clatskanie, Corvallis is hotter, drier, and has more continentality, meaning colder, wetter winters and hotter, dryer summers.

While these are the average site conditions, at the time of sampling, both Clatskanie and Corvallis experienced the lowest temperatures recorded for those dates over the past 38 years (Figure 2 B-E, solid line). Minimum temperatures ranged from $-10^{\circ} \mathrm{C}$ to $0^{\circ} \mathrm{C}$ and maximum temperatures never reached higher than $3-5^{\circ} \mathrm{C}$. This is a key detail as starch synthesis and degradation enzymes cease to perform under $3-5^{\circ} \mathrm{C}$ (Pollock \& Lloyd, 1987), thus these short-term temperature drops may have influenced our measures (Figure 2 B-E).

\section{Total phenotypic variation}

Across all tissues measured, NSC concentrations were highest in branches (Clatskanie: $30.8 \pm 8.3 \mathrm{mg}^{*} \mathrm{~g}^{-1}$, Corvallis: $30.3+-6.2 \mathrm{mg}^{*} \mathrm{~g}^{-1}$ ) and lowest in stems (Clatskanie: $15.6+-6.0 \mathrm{mg}^{*} \mathrm{~g}^{-1}$ ) (Table $1 \&$ S2, Figure $\mathrm{S} 1)$. The proportion of total NSCs in starch ranged from $0.10+-0.08$ in branches in Corvallis to $0.28+-$ 0.18 in roots in Clatskanie (Table $1 \&$ S2, Figure S1).

\section{The genetic contribution $(G)$}

We found heritable variation in branches for both total NSCs and proportion of NSCs in starch (Table 1, Branch $\mathrm{H}^{2} \mathrm{TNC}=0.19$, Branch $\mathrm{H}^{2}$ PropStarch $=0.31$ ). As previously reported, this is similar heritability as total NSC storage in P. trichocarpa stems and roots (Table S1; Blumstein et al., 2020). Here we found that the proportion of starch to total stores is also heritable in roots (Root $\mathrm{H}^{2}$ PropStarch $=0.37$ ), but not stems (Stem $\mathrm{H}^{2}$ PropStarch $=0.01$ ).

Branch genetic variation does not exhibit high degrees of across population variation in either total NSCs or proportion of stores in starch $\left(\mathrm{Q}_{\mathrm{st} \text { TNC }}=0.07, \mathrm{Q}_{\mathrm{st} \text { Proportion }}=0.04\right.$; Table 1). This stands in contrast to stems and roots, which demonstrate extensive differentiation across populations in total stores $\left(\mathrm{Q}_{\mathrm{st}}\right.$ Roots $\left.=0.30, \mathrm{Q}_{\mathrm{st} \text { Stems }}=0.31\right)$ and stem partitioning between sugar and starch $\left(\mathrm{Q}_{\mathrm{st}}\right.$ Stems $\left.=0.66\right)$ (Table S2). However, the finding of high $Q_{\text {st }}$ value for stems in the partitioning between sugar and starch is unlikely biologically meaningful. $\mathrm{H}^{2}$ for stems is only 0.01 for this trait, thus the high $\mathrm{Q}_{\mathrm{st}}$ value is calculated using just $1 \%$ of the phenotypic variation measured (Figure S4).

Plasticity: Environmental Contribution (E) 
The proportion of NSC that trees put into starch vs. sugar is a plastic trait by both metrics of plasticity, RDPI and $S$ (Table $2, \mathrm{RDPI}_{\text {proportion }}=0.50, \mathrm{~S}_{\text {proportion }}=0.75$ ). This plastic variation is largely attributable to the effect of garden, which explains $97 \%$ of total plasticity (equation 7; Table 2, Figure 3). On average, Corvallis has higher sugar concentrations and lower starch concentrations, while Clatskanie has higher starch concentrations and lower sugar concentrations (Figures 3B \& S2, Table 1). This pattern is reflected in the proportion of NSC stores in starch, where the proportion of starch to total stores in Corvallis is $50 \%$ more than in Clatskanie (Figure 3B). Thus, there is a clear difference in the degree to which total stores are partitioned between sugar and starch within each garden.

In contrast, total NSC stores are only considered environmentally plastic by one metric $\left(\mathrm{RDPI}_{\mathrm{TNC}}=0.03\right.$, $\left.\mathrm{S}_{\mathrm{TNC}}=0.43\right)$. Only $54 \%$ of the plastic variation $(S)$ measured is explained by environment, while the rest is attributed to GxE effects. Thus, we find high genetic variation in TNC across the gardens, but low plasticity and almost no difference between the two gardens in average total NSC concentrations $\left(\Delta_{\text {garden }}=\right.$ $0.5 \mathrm{mg}^{*} \mathrm{~g}-1$, Table 1, Figure 3A).

\section{Plasticity: Genotype-by-Environment Contribution (GxE)}

Genotype-by-environment interactions explain almost $50 \%$ of the variation between gardens in total NSC stores (Table 12 Figure 3A), but only $3 \%$ of the variation between gardens in the proportion of NSC in starch (Table 2, Figure 3B). Thus, genetic differences explain most of the variation in total NSC stores, while plasticity explains most of the variation in the proportion of starch vs. sugar.

In addition, some genotypes are more plastic than others, particularly in the amount of NSC they allocate to starch (Table 2, Figure 4). This pattern of increasing plasticity follows a latitudinal trend, where northern populations are more plastic in each trait measured than southern populations (Figure 4). However, while data trend this way, they are not significant at the 0.05 level (Figure 4).

\section{Discussion}

Genetic $(G)$ variation in both total stores and partitioning between sugar and starch

Genetic variation in traits act as the raw material with which populations can adapt to novel stress. Here, we found heritable genetic variation in total NSC concentrations (sugar + starch) in the branches of black cottonwood. Our results reveal that these trees could potentially evolve greater NSC storage in response to increased stress. An increase in the concentration of NSC a tree stores may confer enhanced resilience during times of photosynthetically limiting stress by serving as a fuel source or osmotic reservoir (Dietze et al., 2014; Henrik Hartmann et al., 2018; H. Hartmann \& Trumbore, 2016; O'Brien et al., 2014; Wiley \& Helliker, 2012). Experimental and observational studies have demonstrated that trees will draw down NSC stores when experiencing photosynthetically limiting environmental conditions (Adams et al., 2013; Adams et al., 2017; Henrik Hartmann, Ziegler, Trumbore, \& Knapp, 2013; Landhäusser \& Lieffers, 2011; Sevanto et al., 2014), such as drought, suggesting that NSCs may be serving a critical metabolic function. For example, across a study of 10 tropical species of seedlings, species were found to live $\sim 1$ day longer under drought for each additional mg/g of NSC stores they held (O'Brien et al., 2014). Thus, even small changes to heritable storage amounts may have large effects. Given that climate forecasts generally predict more extreme weather events (IPCC, 2013b), the existence of heritable variation in total NSC stores may be crucial for tree populations to evolve in response to climate-driven selection in the future.

In addition to total storage, the proportion of stores individuals put into starch versus sugar at any given time may be crucial for withstanding future climate-driven selection. We also found heritable variation in the proportion of these total stores residing in insoluble starch for branches, stems, and roots (Table 1, Table S2). Across most winter deciduous species, the proportion of total stores in starch is at its lowest in the winter, particularly in January, the month we sampled in (Furze et al., 2019; Martínez-Vilalta et al., 2016). This is thought to be because the rate of starch degradation and synthesis is controlled in part by enzymes with different temperature sensitivities. Starch degradation enzymes are less sensitive to low temperatures than starch synthesis enzymes (Pollock \& Lloyd, 1987), although below $3-5^{\circ} \mathrm{C}$ both degradation and synthesis 
enzymes cease to function. Thus, at low temperatures (but still above $3-5^{\circ} \mathrm{C}$ ) starch is degraded, leading to a corresponding increase of sugar in cells (Zwieniecki, Tixier, \& Sperling, 2015). This newly available pool of sugar can be used for maintenance respiration and may confer an increased cold tolerance to individuals or even signal when to break dormancy in spring (Aude Tixier, Gambetta, Godfrey, Orozco, \& Zwieniecki, 2019). Thus, being sensitive to changes in temperature and shifting stores between starch and sugar may be critical for tree survival under future, more chaotic climate regimes. Our results indicate that there is genetic variation in if or how trees shift stores between starch and sugar. This opens the possibility that trees can adapt their allocation strategy to better fit a changing, more stressful climate.

Although we found heritable variation in both branch total NSC stores and proportion of stores in starch, we did not find evidence that this variation was currently locally adapted. Differentiation across populations in genetic variation of these traits is minimal. The lack of adaptive signatures in branch total NSC stores stands in contrast to adaptive differentiation previously reported for stems and roots. One reason for this divergence may be that branches are the most proximal of the three tissues to carbon sources (leaves) and some sinks (buds and flowers). Over the course of a year, branch NSC stores fluctuate much more than roots or stems as they are the first storage sink to fill with new photosynthates and the first to be drawn down in spring (Furze et al., 2019). This pattern could also be caused by the fact that black cottonwoods have photosynthetic bark. Branches are exposed to more sunlight than stems and roots and thus may see a higher degree of variation in NSC produced via opportunistic bark photosynthesis. Together, these sources of variation may have a genetic signal, but the other sources of fluctuations may mask the genetic variation in storage preventing selection from effectively causing genetic differentiation.

Environmental (E) plasticity in partitioning between sugar and starch

Immediate response to stress depends on an organism's ability to plastically adjust trait values to accommodate changing environments. The degree to which an organism can plastically respond will, in many cases, determine its ability to survive stress. Here, we found extensive plastic variation due to environmental response in the proportion of NSC stores in starch versus sugar (Table 2, Figure 3, solid black lines). In Clatskanie an average of $20 \%$ of total NSC stores were found in starch, while only half that amount was found in Corvallis (Figure 3).

Clatskanie has a coastal climate with rainfall spread throughout the year and small temperature differences between winter and summer (Figure 2). In contrast, Corvallis has a continental climate which regularly experiences extreme temperatures and long periods without rainfall (Figure 2). Thus, these results may reflect the differential enzymatic sensitivities of starch degradation and synthesis to average climatic conditions at these two sites (Pollock \& Lloyd, 1987; Aude Tixier et al., 2019). The warmer average temperatures in Clatskanie could have led to a higher proportion of NSC being left in starch while the colder, more stressful conditions of Corvallis resulted in more sugar storage.

The observed plasticity in proportion of starch storage could also be driven by the weather patterns on the dates of sampling. We happened to collect woody tissues on the coldest days recorded over the past 38 years in Clatskanie and extremely cold days in Corvallis (Figure 3). Low temperatures in Clatskanie fell below $-10^{\circ} \mathrm{C}$ some days and highs never went above $4^{\circ} \mathrm{C}$, within the minimum temperature range that starch synthesis and degradation enzymes can work (Pollock \& Lloyd, 1987). The sharp drop in temperatures due to the polar vortex may have halted enzymatic activity entirely. Thus, instead of starch steadily degrading to sugar as temperatures drop, the quick temperature change may have prevented starch from degrading further. Conversely, we travelled to Corvallis after sampling in Clatskanie, where the temperature reached just above $5^{\circ} \mathrm{C}$ on our sample dates; just above the minimum temperature range for enzymatic activity. Thus, starch may have degraded into sugar in trees at this site. Such a quick change could be possible given that starch synthesis and degradation have been observed on diurnal scales (A. Tixier et al., 2018).

It is difficult to pinpoint whether the plasticity in the proportion of NSC in starch between the two gardens was attributable to the average climate of the two sites, or the weather at the time of sampling. However, there is mounting evidence that this plasticity in the synthesis and degradation of starch in plants is critical 
for seasonal signaling in plants (Gibon et al., 2009; Palacio, Gunter, Sala, Korner, \& Millard, 2014; Aude Tixier et al., 2019). Branch NSC stores begin to synthesize from sugar into starch as temperatures rise in spring (Furze et al., 2019; Martínez-Vilalta et al., 2016), and this process likely occurs faster in branches than in roots because branches are exposed to air and not insulated in the soil. Thus, temperature gradients across the plant may drive the movement of carbohydrates upward in spring to support leaf flush and stem growth (Sperling, Silva, Tixier, Theroux-Rancourt, \& Zwieniecki, 2017). This synthesis of starch or movement of carbohydrates could be the signal plants sense in spring to break dormancy or initiate leafout. Thus, it may be this plasticity in the conversion of sugar to starch that is in part driving observed plasticity in phenological timing, a key trait for future tree adaptation to climate change (Alberto et al., 2011; Hall et al., 2007; Keller et al., 2011).

While the pattern of plastic variation between gardens is clear, it is not yet known what the biological meaning of a $10 \%$ change in the proportion of stores in starch could be as there are few studies of starch variation in response to environment in trees. The degradation of starch and resultant increase in sugars has been demonstrated to confer freezing and drought resistance to herbaceous plants, particularly Arabidopsis (reviewed in Thalmann \& Santelia, 2017). However, these studies are conducted in a laboratory on leaf tissues in herbaceous plants using different NSC quantification measures, which makes the ability to draw meaningful comparisons difficult (Landhausser et al., 2018). Of the few studies performed in trees using similar methods to ours, there is evidence that a $10 \%$ change in proportion of starch is substantial. In Populus tremuloides clones, the proportion of total stores in starch in branches can vary between 0 and $13 \%$ seasonally (Landhäusser \& Lieffers, 2003). Additionally, across four deciduous species measured in the dormant season (January), the proportion of stores in starch can vary between 8 and $28 \%$ (Furze et al., 2019). Together, these suggest that a $10 \%$ difference between the two gardens may be a biologically relevant shift. Overall, our findings highlight the need for more research on starch conversion in tree species in the lab and in situ .

\section{Environmental plasticity in total NSC stores unveiled when tree size is considered}

While partitioning of stores between sugar and starch is plastic, we found total NSC stores to be the same, on average, between the two gardens. This is particularly interesting as the timing of leaf out and growth rates of trees significantly differ between the two sites. In Clatskanie, leaves come out earlier than Corvallis, potentially giving the Clatskanie trees a greater opportunity to produce carbon compared to the Corvallis trees(Evans et al., 2014). This carbon advantage is reflected in the diameters of trees at both sites, where trees in Clatskanie are almost double the size of trees in Corvallis (Figure 5). However, both sites average the same total NSC storage concentrations. Without the growth data, total NSC stores appear to have no environmentally driven plasticity, however with the growth data, the lack of difference between the two sites could actually be indicative of environmental plasticity in a tradeoff between the growth and storage. Trees growing in more variable or extreme conditions may "bet-hedge" by storing more NSC at the expense of other uses, such as growth (Sala, Woodruff, \& Meinzer, 2012; Wiley \& Helliker, 2012). This particular pattern has been shown in Arabidopsis, where plants favor storage over growth when photosynthetic productivity declines (Gibon et al., 2009; Smith \& Stitt, 2007). Our results here suggest that this may be similar in the case in black cottonwoods, where genotypes grown in the continental garden (Corvallis), with larger temperature and precipitation extremes, maintain the same concentration of stores, but down-regulate growth to compensate. Thus, proportionally more energy is allocated to storage at the expense of growth in the more stressful environment.

\section{Genotype-by-environment (GxE) plasticity in total stores, but not in proportion of stores in starch}

Genetic variation in environmental response could provide a key mechanism through which populations can evolve a more adaptive response to future environmental stress. Here, we found that plastic variation in total storage is almost entirely comprised of genotype-by-environment interactions. The average total NSC storage concentrations between the two gardens only differ by $0.5 \mathrm{mg} \mathrm{g}^{*}-1$, but individual genotypes differ by -3.4 to $3.3 \mathrm{mg}^{*} \mathrm{~g}-1$ between the two gardens. This flexibility amongst genotypes may be the result of intrinsic differences in response to environment (Des Marais et al., 2013) and could explain why previous 
studies have failed to converge on a consistent response to stress to date (Adams et al., 2017; Thalmann \& Santelia, 2017). These works have found that NSC concentrations may decrease, increase, or remain stable in response to stressors such as drought and extreme temperature. Thus, our work underscores the importance of controlling for genetics when conducting any NSC manipulations, as the high heritability and GxE of the trait can confound interpretation of results.

In contrast, plastic variation in the proportion of NSC stores in starch is almost entirely attributed to differences in environment and not GxE interactions. This finding further supports a model whereby the amount of NSC residing in starch is driven by intrinsic enzymatic environmental limits. While GxE for this trait is lower than the amount of GxE for total NSC stores, there is a slight latitudinal pattern in the proportion of starch GxE variation (Figure 4, S3). The trending correlation between latitude and the proportion of starch RDPI suggests that some genotypes may be more plastic than others in their ability to move between sugar and starch, however it is not significant (Figure 5). In particular, genotypes from northern populations appear to have more flexibility between the two gardens. Put another way, northern genotypes are more responsive to environmental differences between the two sites. One possible explanation for this trend is that their starch degradation enzymes may be more sensitive to temperature fluctuations or are able to continue to act at slightly lower temperatures than those from southern populations. This may be beneficial to trees in northern latitudes experiencing extreme temperature lows and large temperature swings throughout the day. Although the amount of variation explained by GxE interactions may be small, the importance for immediate environmental response may be very important and is worth further investigation.

\section{Conclusion}

Our study is the first of its kind to study heritable variation and plasticity in branch nonstructural carbohydrate storage. NSC stores have been demonstrated over the past decade to confer resilience to climate stress in woody species and are likely critical for plant response to future climate. In nearly all previous experiments on NSC variation, it was simply assumed that the variation observed in the experiment is due to predictable responses to environmental variation or perturbation (E). We demonstrate that, in fact, a significant amount of biologically meaningful variation in NSCs is due to genetic variation between trees. This means that there are genetic mechanisms that regulate differences in NSC storage, even between trees grown in the same environment. More importantly, we find extensive variation across trees in their response to environmental variation. Overall, we demonstrate that the concentration of total NSCs that trees store as well as the degree to which they partition these stores between soluble sugars and starch have both adaptive genetic variation and plasticity, potentially bolstering forest tree species against climate change in the short-and-long term.

\section{Works Cited}

Adams, H. D., Germino, M. J., Breshears, D. D., Barron-Gafford, G. A., Guardiola-Claramonte, M., Zou, C. B., \& Huxman, T. E. (2013). Nonstructural leaf carbohydrate dynamics of Pinus edulis during droughtinduced tree mortality reveal role for carbon metabolism in mortality mechanism. New Phytol, 197 (4), 1142-1151. doi:10.1111/nph.12102

Adams, H. D., Zeppel, M. J. B., Anderegg, W. R. L., Hartmann, H., Landhausser, S. M., Tissue, D. T., . . . McDowell, N. G. (2017). A multi-species synthesis of physiological mechanisms in drought-induced tree mortality. Nat Ecol Evol, 1 (9), 1285-1291. doi:10.1038/s41559-017-0248-x

Aitken, S. N., Yeaman, S., Holliday, J. A., Wang, T., \& Curtis-McLane, S. (2008). Adaptation, migration or extirpation: climate change outcomes for tree populations. Evol Appl, 1 (1), 95-111. doi:10.1111/j.17524571.2007.00013.x

Alberto, F., Bouffier, L., Louvet, J. M., Lamy, J. B., Delzon, S., \& Kremer, A. (2011). Adaptive responses for seed and leaf phenology in natural populations of sessile oak along an altitudinal gradient.J Evol Biol, 24 (7), 1442-1454. doi:10.1111/j.1420-9101.2011.02277.x

Allen, C. D., Macalady, A. K., Chenchouni, H., Bachelet, D., McDowell, N., Vennetier, M., . . . Cobb, N. 
(2010). A global overview of drought and heat-induced tree mortality reveals emerging climate change risks for forests. Forest Ecology and Management, 259 (4), 660-684. doi:10.1016/j.foreco.2009.09.001

Anderegg, W. R., Hicke, J. A., Fisher, R. A., Allen, C. D., Aukema, J., Bentz, B., . . . Zeppel, M. (2015). Tree mortality from drought, insects, and their interactions in a changing climate. New Phytol, 208 (3), 674-683. doi:10.1111/nph.13477

Anderegg, W. R., Klein, T., Bartlett, M., Sack, L., Pellegrini, A. F., Choat, B., \& Jansen, S. (2016). Metaanalysis reveals that hydraulic traits explain cross-species patterns of drought-induced tree mortality across the globe. Proc Natl Acad Sci U S A, 113 (18), 5024-5029. doi:10.1073/pnas.1525678113

Anderson, J. T., Inouye, D. W., McKinney, A. M., Colautti, R. I., \& Mitchell-Olds, T. (2012). Phenotypic plasticity and adaptive evolution contribute to advancing flowering phenology in response to climate change. Proc Biol Sci, 279 (1743), 3843-3852. doi:10.1098/rspb.2012.1051

Blumstein, M., Richardson, A. D., Weston, D. J., Zhang, J., Wellington, M., \& Hopkins, R. (2020). A new perspective on ecological prediction reveals limits to climate adaptation in a temperate tree species. Current Biology, 30 , 1447-1453.

Chapin III, S., Schulze, E.-D., \& Mooney, H. A. (1990). The ecology and economics of storage in plants. Annual Reviews, 21 , 423-447.

Chen, H.-J., Chen, J.-Y., \& Wang, S.-J. (2007). Molecular regulation of starch accumulation in rice seedling leaves in response to salt stress. Acta Physiologiae Plantarum, 30 (2), 135-142. doi:10.1007/s11738-007-0101y

Chow, P. S., \& Landhausser, S. M. (2004). A method for routine measurements of total sugar and starch content in woody plant tissues. Tree Physiology, 24, 1129-1136.

Davis, M. B., Shaw, R. G., \& Etterson, J. R. (2005). Evolutionary responses to changing climate. Ecology, 86 (7), 1704-1714.

Des Marais, D. L., Hernandez, K. M., \& Juenger, T. E. (2013). Genotype-by-Environment Interaction and Plasticity: Exploring Genomic Responses of Plants to the Abiotic Environment. Annual Review of Ecology, Evolution, and Systematics, 44 (1), 5-29. doi:10.1146/annurev-ecolsys-110512-135806

Dietze, M. C., Sala, A., Carbone, M. S., Czimczik, C. I., Mantooth, J. A., Richardson, A. D., \& Vargas, R. (2014). Nonstructural carbon in woody plants. Annu Rev Plant Biol, 65 , 667-687. doi:10.1146/annurevarplant-050213-040054

Evans, L. M., Slavov, G. T., Rodgers-Melnick, E., Martin, J., Ranjan, P., Muchero, W., . . . DiFazio, S. P. (2014). Population genomics of Populus trichocarpa identifies signatures of selection and adaptive trait associations. Nat Genet, 46 (10), 1089-1096. doi:10.1038/ng.3075

Furze, M. E., Huggett, B. A., Aubrecht, D. M., Stolz, C. D., Carbone, M. S., \& Richardson, A. D. (2019). Whole-tree nonstructural carbohydrate storage and seasonal dynamics in five temperate species. New Phytol, 221 (3), 1466-1477. doi:10.1111/nph.15462

Gibon, Y., Pyl, E. T., Sulpice, R., Lunn, J. E., Hohne, M., Gunther, M., \& Stitt, M. (2009). Adjustment of growth, starch turnover, protein content and central metabolism to a decrease of the carbon supply when Arabidopsis is grown in very short photoperiods. Plant Cell Environ, 32 (7), 859-874. doi:10.1111/j.13653040.2009.01965.x

Goodrich, B., Gabry, J., Ali, I., \& Brilleman, S. (2019). rstanarm: Bayesian applied regression modelin via Stan.

Goyal, A. (2007). Osmoregulation in Dunaliella, Part II: Photosynthesis and starch contribute carbon for glycerol synthesis during a salt stress in Dunaliella tertiolecta. Plant Physiol Biochem, 45 (9), 705-710. doi:10.1016/j.plaphy.2007.05.009 
Hall, D., Luquez, V., Garcia, V. M., St Onge, K. R., Jansson, S., \& Ingvarsson, P. K. (2007). Adaptive population differentiation in phenology across a latitudinal gradient in European aspen (Populus tremula, L.): a comparison of neutral markers, candidate genes and phenotypic traits. Evolution, 61 (12), 2849-2860. doi:10.1111/j.1558-5646.2007.00230.x

Hartmann, H., Adams, H. D., Hammond, W. M., Hoch, G., Landhausser, S. M., Wiley, E., \& Zaehle, S. (2018). Identifying differences in carbohydrate dynamics of seedlings and mature trees to improve carbon allocation in models for trees and forests. Environmental and Experimental Botany, 152 , 7-18. doi:10.1016/j.envexpbot.2018.03.011

Hartmann, H., \& Trumbore, S. (2016). Understanding the roles of nonstructural carbohydrates in forest trees - from what we can measure to what we want to know. New Phytol, 211 (2), 386-403. doi:10.1111/nph.13955

Hartmann, H., Ziegler, W., Trumbore, S., \& Knapp, A. (2013). Lethal drought leads to reduction in nonstructural carbohydrates in Norway spruce tree roots but not in the canopy. Functional Ecology, 27 (2), 413-427. doi:10.1111/1365-2435.12046

Hoermiller, II, Naegele, T., Augustin, H., Stutz, S., Weckwerth, W., \& Heyer, A. G. (2017). Subcellular reprogramming of metabolism during cold acclimation in Arabidopsis thaliana. Plant Cell Environ, 40 (5), 602-610. doi:10.1111/pce.12836

Hufkens, K., Basler, J. D., Milliman, T., Melaas, E., \& Richardson, A. D. (2018). An interated phenology modelling framework in R: Phenology modelling with phenor. Methods in Ecology and Evolution, 9 , 1-10.

IPCC. (2013a). Annex I: Atlas of Global and Regional Climate Projections In T. F. Stocker, D. Qin, G.-K. Plattner, M. Tignor, S. K. Allen, J. Boschung, A. Nauels, Y. Xia, V. Bex, \& P. M. Midgley (Eds.), Climate Change 2013: The Physical Science Basis. Contribution of Working Group I to the Fifth Assessment Report of the Intergovernmental Panel on Climate Change (pp. 1311-1394). Cambridge, United Kingdom and New York, NY, USA: Cambridge University Press.

IPCC. (2013b). Climate Change 2013: The Physical Science Basis. Contribution of Working Group I to the Fifth Assessment Report of the Intergovernmental Panel on Climate Change (T. F. Stocker, D. Qin, G.-K. Plattner, M. Tignor, S. K. Allen, J. Boschung, A. Nauels, Y. Xia, V. Bex, \& P. M. Midgley Eds.). Cambridge, United Kingdom and New York, NY, USA: Cambridge University Press.

Josephs, E. B., Berg, J. J., Ross-Ibarra, J., \& Coop, G. (2019). Detecting adaptive differentiation in structured populations with genomic data and common gardens. Genetics, 211 . doi:10.1101/368506

Kanai, M., Higuchi, K., Hagihara, T., Konishi, T., Ishii, T., Fujita, N., . . . Tadano, T. (2007). Common reed produces starch granules at the shoot base in response to salt stress. New Phytol, 176 (3), 572-580. doi:10.1111/j.1469-8137.2007.02188.x

Kaplan, F., \& Guy, C. L. (2004). beta-Amylase induction and the protective role of maltose during temperature shock. Plant Physiol, 135 (3), 1674-1684. doi:10.1104/pp.104.040808

Kaplan, F., \& Guy, C. L. (2005). RNA interference of Arabidopsis beta-amylase8 prevents maltose accumulation upon cold shock and increases sensitivity of PSII photochemical efficiency to freezing stress. Plant $J$, 44 (5), 730-743. doi:10.1111/j.1365-313X.2005.02565.x

Keller, S. R., Soolanayakanahally, R. Y., Guy, R. D., Silim, S. N., Olson, M. S., \& Tiffin, P. (2011). Climate-driven local adaptation of ecophysiology and phenology in balsam poplar, Populus balsamifera L. (Salicaceae). Am J Bot, 98 (1), 99-108. doi:10.3732/ajb.1000317

Kempa, S., Krasensky, J., Dal Santo, S., Kopka, J., \& Jonak, C. (2008). A central role of abscisic acid in stress-regulated carbohydrate metabolism. PLoS One, 3 (12), e3935. doi:10.1371/journal.pone.0003935

Krasensky, J., \& Jonak, C. (2012). Drought, salt, and temperature stress-induced metabolic rearrangements and regulatory networks. J Exp Bot, 63 (4), 1593-1608. doi:10.1093/jxb/err460 
Landhausser, S. M., Chow, P. S., Dickman, L. T., Furze, M. E., Kuhlman, I., Schmid, S., . . . Adams, H. D. (2018). Standardized protocols and procedures can precisely and accurately quantify non-structural carbohydrates. Tree Physiol, 38 (12), 1764-1778. doi:10.1093/treephys/tpy118

Landhausser, S. M., \& Lieffers, V. J. (2003). Seasonal changes in carbohydrate reserves in mature northern Populus tremuloides clones. Trees, 17 (6), 471-476. doi:10.1007/s00468-003-0263-1

Landhausser, S. M., \& Lieffers, V. J. (2011). Defoliation increases risk of carbon starvation in root systems of mature aspen. Trees, 26 (2), 653-661. doi:10.1007/s00468-011-0633-z

Ma, T., Wang, J., Zhou, G., Yue, Z., Hu, Q., Chen, Y., . . . Liu, J. (2013). Genomic insights into salt adaptation in a desert poplar. Nat Commun, 4 , 2797. doi:10.1038/ncomms3797

Martinez-Vilalta, J., Sala, A., Asensio, D., Galiano, L., Hoch, G., Palacio, S., . . . Lloret, F. (2016). Dynamics of non-structural carbohydrates in terrestrial plants: a global synthesis.Ecological Monographs, 86 (4), 495-516. doi:10.1002/ecm.1231

McDowell, N., Allen, C. D., Anderson-Teixeira, K., Brando, P., Brienen, R., Chambers, J., . . . Xu, X. (2018). Drivers and mechanisms of tree mortality in moist tropical forests. New Phytol, 219 (3), 851-869. doi:10.1111/nph.15027

McDowell, N., Pockman, W. T., Allen, C. D., Breshears, D. D., Cobb, N., Kolb, T., . . . Yepez, E. A. (2008). Mechanisms of plant survival and mortality during drought: why do some plants survive while others succumb to drought? New Phytol, 178 (4), 719-739. doi:10.1111/j.1469-8137.2008.02436.x

Mitchell, P. J., O'Grady, A. P., Tissue, D. T., White, D. A., Ottenschlaeger, M. L., \& Pinkard, E. A. (2013). Drought response strategies define the relative contributions of hydraulic dysfunction and carbohydrate depletion during tree mortality. New Phytol, 197 (3), 862-872. doi:10.1111/nph.12064

Nagao, M., Minami, A., Arakawa, K., Fujikawa, S., \& Takezawa, D. (2005). Rapid degradation of starch in chloroplasts and concomitant accumulation of soluble sugars associated with ABA-induced freezing tolerance in the moss Physcomitrella patens. J Plant Physiol, 162 (2), 169-180. doi:10.1016/j.jplph.2004.06.012

Nuismer, S. L., \& Gandon, S. (2008). Moving beyond common-garden and transplant designs: insight into the causes of local adaptation in species interactions. Am Nat, 171 (5), 658-668. doi:10.1086/587077

Nychka, D., Furrer, R., Paige, J., \& Sain, S. (2017). fields: Tools for spatial data. Boulder, CO, USA: University Corporation for Atmospheric Research. Retrieved from https://github.com/NCAR/Fields

O'Brien, M. J., Leuzinger, S., Philipson, C. D., Tay, J., \& Hector, A. (2014). Drought survival of tropical tree seedlings enhanced by non-structural carbohydrate levels. Nature Climate Change, 4 (8), 710-714. doi:10.1038/nclimate2281

Oksanen, J., Blanchet, G., Friendly, M., Kindt, R., Legendre, P., McGlinn, D., . . . Wagner, H. (2018). vegan: Community Ecology Package.R Package. version 2.5-3. Retrieved from https://CRAN.Rproject.org $/$ package $=$ vegan

Oleksyn, J., Zytkowiak, R., Karolewski, P., Reich, P. B., \& Tjoelker, M. G. (1999). Genetic and environmental control of seasonal carbohydrate dynamics in tress of diverse Pinus sylvestris populations. Tree Physiology, 20 , 837-847.

Palacio, S., Gunter, H., Sala, A., Korner, C., \& Millard, P. (2014). Does carbon storage limit tree growth? New Phytologist, 201 , 1096-1100.

Plavcova, L., \& Jansen, S. (2015). The Role of Xylem Parenchyma in the Storage and Utilization of Nonstructural Carbohydrates. InFunctional and Ecological Xylem Anatomy (pp. 209-234).

Pollock, C. J., \& Lloyd, E. J. (1987). The effect of low temperatures upon starch, sucrose, and fructan synthesis in leaves. Annals of Botany, $60,231-235$. 
Pritzkow, C., Williamson, V., Szota, C., Trouve, R., \& Arndt, S. K. (2020). Phenotypic plasticity and genetic adaptation of functional traits influences intra-specific variation in hydraulic efficiency and safety. Tree Physiol, 40 (2), 215-229. doi:10.1093/treephys/tpz121

Richardson, A. D., Carbone, M. S., Keenan, T. F., Czimczik, C. I., Hollinger, D. Y., Murakami, P., . . . Xu, X. (2013). Seasonal dynamics and age of stemwood nonstructural carbohydrates in temperate forest trees. New Phytol, 197 (3), 850-861. doi:10.1111/nph.12042

Sala, A., Woodruff, D. R., \& Meinzer, F. C. (2012). Carbon dynamics in trees: feast or famine? Tree Physiol, 32 (6), 764-775. doi:10.1093/treephys/tpr143

Scheiner, S. M., \& Goodnight, C. J. (1984). The comparison of phenotypic plasticity and genetic variation in populations of the grass Danthonia spicata. Evolution, 38 (4).

Scheiner, S. M., \& Lyman, R. F. (1989). The genetics of phenotypic plasticity. Journal of Evolutionary Biology, 2, 95-107.

Sevanto, S., McDowell, N. G., Dickman, L. T., Pangle, R., \& Pockman, W. T. (2014). How do trees die? A test of the hydraulic failure and carbon starvation hypotheses. Plant Cell Environ, 37 (1), 153-161. doi:10.1111/pce.12141

Slavov, G. T., DiFazio, S. P., Martin, J., Schackwitz, W., Muchero, W., Rodgers-Melnick, E., . . Tuskan, G. A. (2012). Genome resequencing reveals multiscale geographic structure and extensive linkage disequilibrium in the forest tree Populus trichocarpa. New Phytol, 196 (3), 713-725. doi:10.1111/j.1469-8137.2012.04258.x

Smith, A. M., \& Stitt, M. (2007). Coordination of carbon supply and plant growth. Plant Cell Environ, 30 (9), 1126-1149. doi:10.1111/j.1365-3040.2007.01708.x

Sperling, O., Silva, L. C. R., Tixier, A., Theroux-Rancourt, G., \& Zwieniecki, M. A. (2017). Temperature gradients assist carbohydrate allocation within trees. Sci Rep, 7 (1), 3265. doi:10.1038/s41598-017-03608-w

Spitze, K. (1993). Population structure in Daphnia obtusa : quantitative genetic and allozymic variation. . Genetics, 135 (25), 367-374.

Stopher, K. V., Walling, C. A., Morris, A., Guinness, F. E., Clutton-Brock, T. H., Pemberton, J. M., \& Nussey, D. H. (2012). Shared spatial effects on quantitative genetic parameters: accounting for spatial autocorrelation and home range overlap reduces estimates of heritability in wild red deer. Evolution, 66 (8), 2411-2426. doi:10.1111/j.1558-5646.2012.01620.x

Team, R. C. D. (2018). R: A Language and Environment for Statistical Computing. Vienna, Austria. Retrieved from https://www.R-project.org/

Team, T. S. D. (2014). RStan Getting Started. Retrieved from http://mc-stan.org/

Thalmann, M., \& Santelia, D. (2017). Starch as a determinant of plant fitness under abiotic stress. New Phytol, 214 (3), 943-951. doi:10.1111/nph.14491

Thornton, P. E., Thornton, M. M., Mayer, B. W., Wei, Y., Devarakonda, R., Vose, R. S., \& Cook, R. B. (2018). Daymet: Daily Surface Weather Data on a 1-km Grid for North America, Version 3.

Tixier, A., Gambetta, G. A., Godfrey, J., Orozco, J., \& Zwieniecki, M. A. (2019). Non-structural Carbohydrates in Dormant Woody Perennials; The Tale of Winter Survival and Spring Arrival. Frontiers in Forests and Global Change, 2 . doi:10.3389/ffgc.2019.00018

Tixier, A., Orozco, J., Roxas, A. A., Earles, J. M., \& Zwieniecki, M. A. (2018). Diurnal Variation in Nonstructural Carbohydrate Storage in Trees: Remobilization and Vertical Mixing. Plant Physiol, 178 (4), 1602-1613. doi:10.1104/pp.18.00923 
Valladares, F., Matesanz, S., Guilhaumon, F., Araujo, M. B., Balaguer, L., Benito-Garzon, M., . . . Thuiller, W. (2014). The effects of phenotypic plasticity and local adaptation on forecasts of species range shifts under climate change. Ecology Letters, 17 (11), 1351-1364. doi:10.1111/ele.12348

Valladares, F., Sanchez-Gomez, D., \& Zavala, M. A. (2006). Quantitative estimation of phenotypic plasticity: bridging the gap between the evolutionary concept and its ecological applications. Journal of Ecology, 94 (6), 1103-1116. doi:10.1111/j.1365-2745.2006.01176.x

Vasseur, F., Pantin, F., \& Vile, D. (2011). Changes in light intensity reveal a major role for carbon balance in Arabidopsis responses to high temperature. Plant Cell Environ, 34 (9), 1563-1576. doi:10.1111/j.13653040.2011.02353.x

Whitlock, M. C., \& Gilbert, K. J. (2012). Q(ST) in a hierarchically structured population. Molecular Ecology Resources, 12 (3), 481-483. doi:10.1111/j.1755-0998.2012.03122.x

Wiley, E., \& Helliker, B. (2012). A re-evaluation of carbon stroage in trees lends greater support for carbon limitation to growth. New Phytologist, 195 , 285-289.

Wortemann, R., Herbette, S., Barigah, T. S., Fumanal, B., Alia, R., Ducousso, A., . . . Cochard, H. (2011). Genotypic variability and phenotypic plasticity of cavitation resistance in Fagus sylvatica L. across Europe. Tree Physiol, 31 (11), 1175-1182. doi:10.1093/treephys/tpr101

Wurth, M. K., Pelaez-Riedl, S., Wright, S. J., \& Korner, C. (2005). Non-structural carbohydrate pools in a tropical forest. Oecologia, 143 (1), 11-24. doi:10.1007/s00442-004-1773-2

Zwieniecki, M. A., Tixier, A., \& Sperling, O. (2015). Temperature-assisted redistribution of carbohydrates in trees. Am J Bot, 102 (8), 1216-1218. doi:10.3732/ajb.1500218

\section{Figures and Tables}

Table 1. Phenotypic means and standard deviations, variance component estimates from equation (1), and parameters for total nonstructural carbohydrate (TNC) storage concentrations and the proportion of total stores in starch of branch tissues of black cottonwood trees.

\begin{tabular}{|c|c|c|c|c|c|c|c|c|c|c|c|}
\hline & Clatskanie & Clatskanie & Corvallis & Corvallis & & & & & & & \\
\hline Branch Trait & $\mu$ & $\sigma$ & $\mu$ & $\sigma$ & $\left(\sigma^{2}\right.$ Gipg $)$ & $\left(\sigma_{\mathrm{Gpg}}^{2}\right)$ & $\left(\sigma_{G p}^{2}\right)$ & $\left(\sigma_{\mathrm{G}}^{2}\right)$ & $\left(\beta_{G}\right)$ & $\mathrm{H}^{2}$ & \\
\hline $\mathrm{TNC}$ & 30.8 & 8.3 & 30.3 & 6.2 & 31.39 & 6.567 & 1.004 & 222.759 & -0.099 & 0.19 & 0 . \\
\hline Proportion & 0.2 & 0.07 & 0.1 & 0.08 & 0.002 & 0.001 & 0 & 0.003 & -0.102 & 0.31 & \\
\hline
\end{tabular}

Table 2. Variance component estimates from equation (4) and parameters for total nonstructural carbohydrate (TNC) storage concentrations and the proportion of total stores in starch of branch tissues of black cottonwood trees.

\begin{tabular}{lllllll}
\hline Branch Trait & $\sigma_{\mathrm{g}}^{2}$ & $\sigma^{2} \mathrm{G}_{\mathrm{G}}$ & $\sigma^{2}{ }_{\mathrm{G}: \mathrm{g}}$ & $\mathrm{RDPI}$ & $\mathrm{S}$ & $(\%)$ of S that is GxE \\
\hline TNC & 2.4 & 3.4 & 3.2 & 0.03 & 0.43 & 46 \\
Proportion & 0.025 & 0.091 & 0.017 & 0.5 & 0.75 & 3 \\
\hline
\end{tabular}

Figure 1. The transplant design. Genotypes were sourced from 17 populations from across western North America and replicated three times each in two common gardens located in Clatskanie and Corvallis. In the winter of 2013-2014, one replicate in Clatskanie and all three replicates in Corvallis were coppiced aboveground and allowed to regrow (shown as small trees). Sample tissues collected in January 2017 are reflected by the purple ovals with the subsequent number of samples taken of each tissue from each garden indicated. 
Figure 2. (A) A principle components analysis (PCA) of the climate over the past 38 years at each of the genotype's source locations and the two common gardens. Dots represent each genotype's source location in climate space, colored by latitude, and the two black triangles represent the common gardens in the climate space. (B-E) The average minimum and maximum temperatures over the past 38 years in Clatskanie and Corvallis (boxplots) as compared to the minimum and maximum temperatures in the year we collected samples (2017, black lines). Samples were collected in (B,D) Clatskanie on January $5^{\text {th }}-$ January $9^{\text {th }}$ and in $(\mathrm{C}, \mathrm{E})$ Corvallis on January $10^{\text {th }}$ - January $11^{\text {th }}$. Data is sourced from Daymet (Thornton et al., 2018). The minimum range of temperatures in which starch formation/degradation can act is highlighted in light gray.

Figure 3. Plasticity between the two common gardens in the two traits measured, (A) total NSC stores (TNC) and (B) the proportion of TNC in starch. Black lines represent the average value across all genotypes, with error bars indicating one standard deviation from the mean. The other lines are colored by latitude and each line represents a genotype, where genotypic values were estimated using equation (1). These plots represent just the genetic, not total, variation measured in our samples, thus are the estimates for genotype once measurement and microenvironmental variation are removed.

Figure 4. The relative distance plasticity index (RDPI) of the (A) proportion of starch to total and (B) total amount of NSC stores plotted by the latitude of each genotype's source location. Black dots represent each genotype's RDPI and the line fits are shaded gray for one standard deviation. A larger RDPI indicates that there is a larger percent change in genotypic trait values between gardens.

Figure 5. (A) Genetic variation in diameter at breast height (DBH) as compared to (B) genetic variation in total nonstructural carbohydrates as measured at each common garden. 

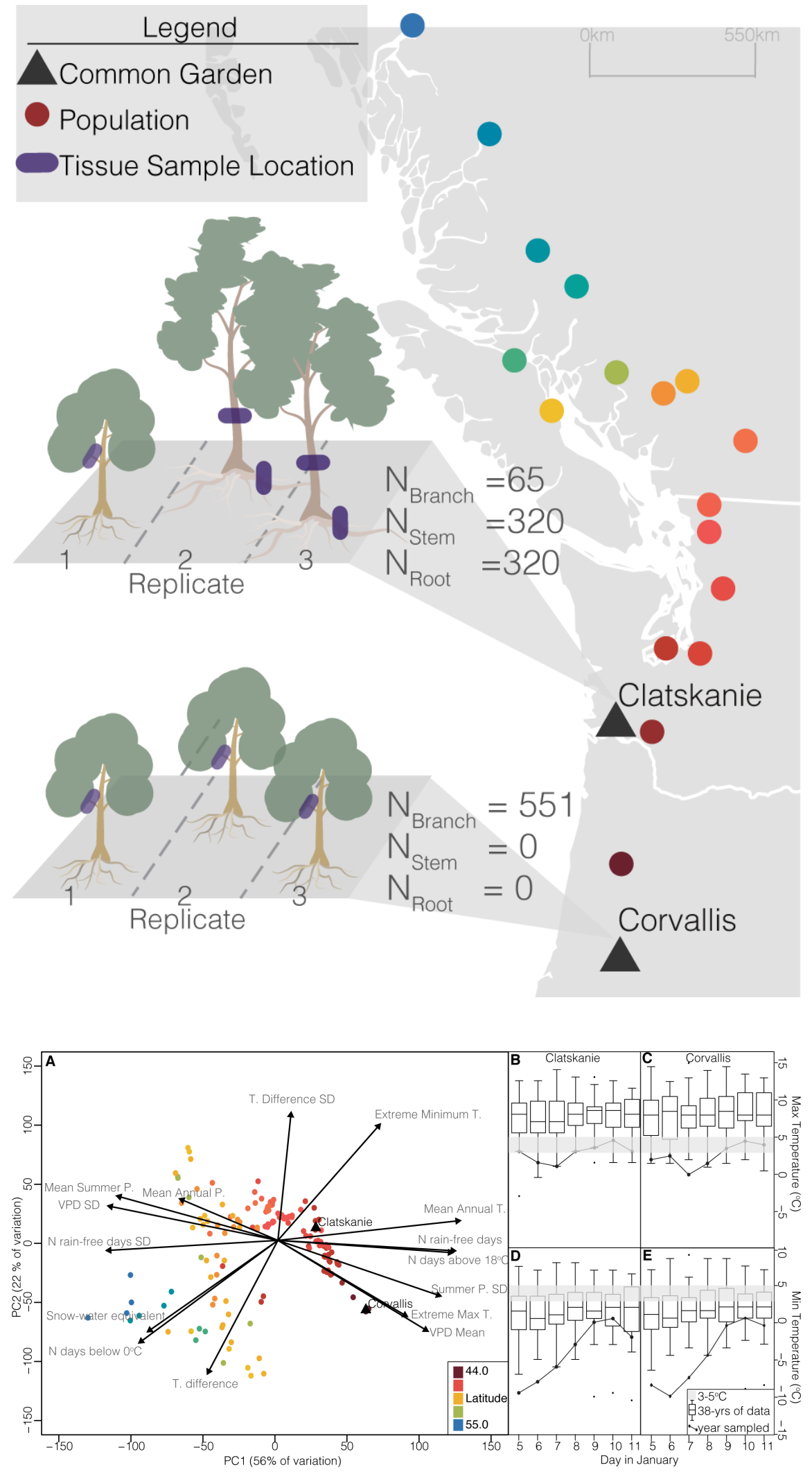


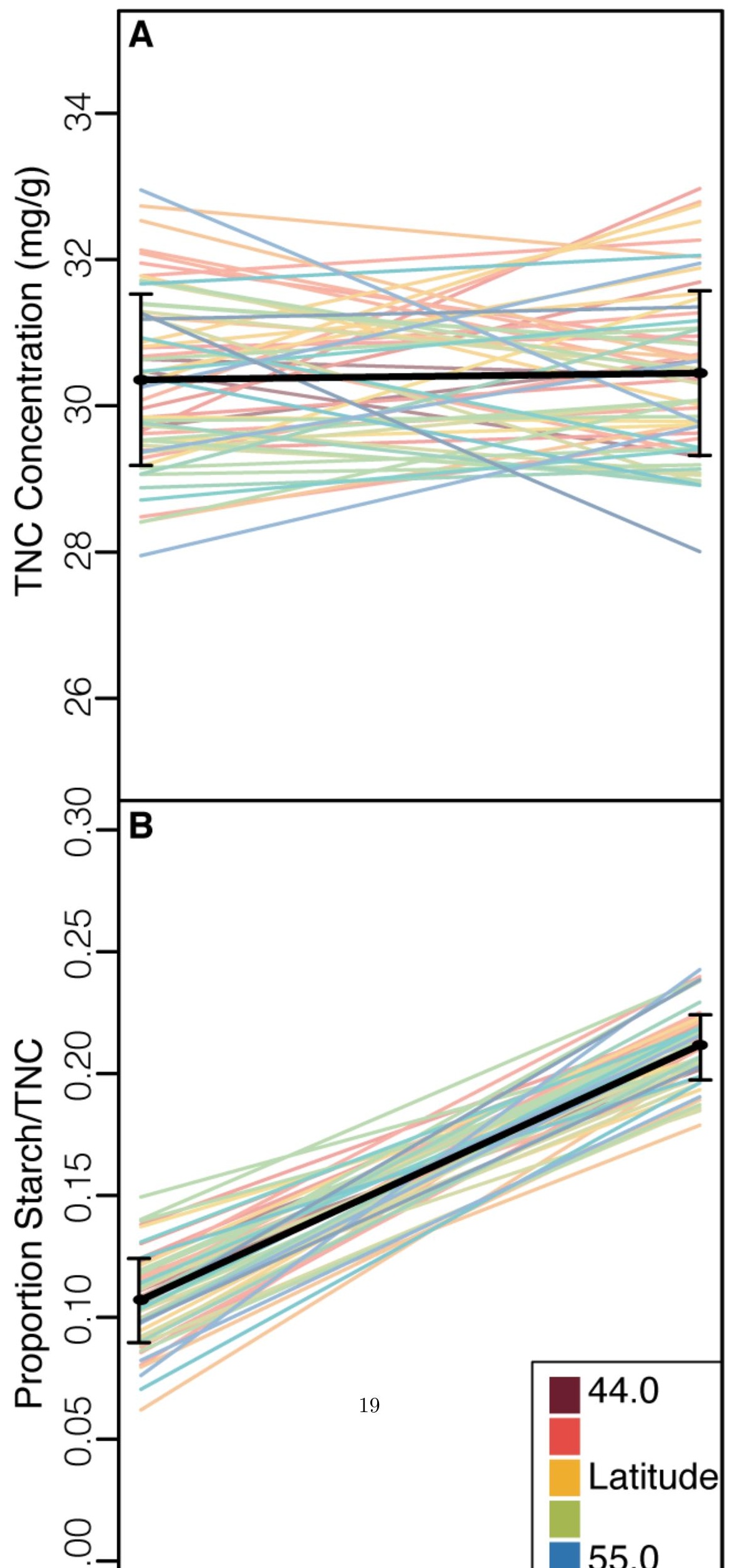



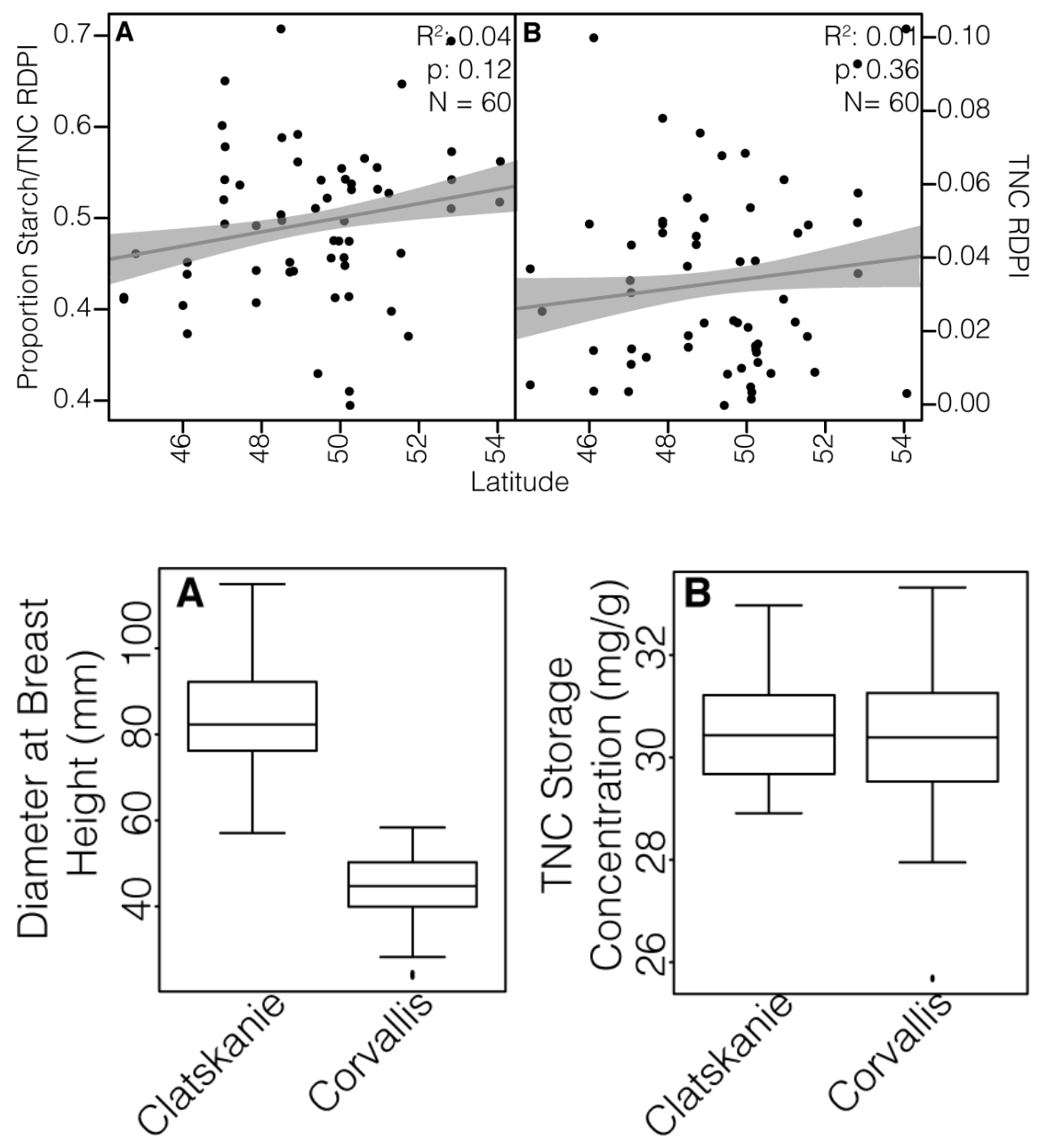